mixtures with binders are being investigated to assess scientifically their suitability for use in road construction and to enable satisfactory specifications to be compiled. One of the first steps has been the designing of satisfactory workability tests for mixes. Bituminous binders are also receiving attention and co-operative research has been arranged with the British Road Tar Research Association. The report also stresses the importance of improving methods for the control of concrete during laying, and for the determination of the factors which influence the design and laying of road slabs and foundations.

In regard to road usage, special interest is attached to the studies of forces applied to roads by various types of vehicles, with the object of correlating these forces with the type of pavement, subsoil and vibration, as well as to attempts to determine the factors in vehicle design and usage which cause damage to the road. The value of scientific knowledge on these points needs no emphasis, while the importance of the attention being given to the problem of skidding is equally apparent. This work aims at determining the factors in vehicle design which induce skidding as well as those factors in road construction and road conditions which promote skidding. An apparatus for assessing the slipperiness of wet surfaces has been designed which has given numerical values for the slipperiness of surfaces in good accord with experience of actual usage of the roads tested. The work has shown, rather surprisingly, that in wet weather roads are in general more slippery in summer than in winter. Other work on road testing machines has been designed to provide some other means of judging durability than waiting for deterioration under normal usage, and it is hoped that the machines being built will form a link in the chain between the laboratory and the road, and ultimately establish a scale against which the probable performance of new forms of materials and construction can be estimated.

The report shows that a good beginning has been made on a programme of research not incommensurate with the expenditure of more than $£ 50,000,000$ involved in the making and upkeep of roads in Great Britain and in the problem of road safety.

\title{
Technical Features of the Normandie
}

\begin{abstract}
$\mathrm{T}$ a joint meeting of the Institution of Mechanical A Engineers with the Société des Ingénieurs Civils de France (British Section) held at the Institution of Electrical Engineers on November 15, M. Jean Marie read a paper on the Normandie. He gave a very interesting description of the precautions taken against fire. The first precaution is the use so far as possible of fireproof materials for floor, ceiling and wall coverings. Where the use of materials such as plywood, linoleums, rubber carpets, etc., was unavoidable, these were made almost incombustible by the use of asbestos and fire-resisting paints. The only really combustible materials are the bedding, linen, clothes and the passengers' and crew's luggage. Tho outbreak of fire is limited by partitioning, six cabins being the maximum in the subdivisions. If a fire, however violent, breaks out in one of them, its extent is limited for more than thirty minutes by the insulating barrier, the temperature remaining normal during this period in the neighbourhood of
\end{abstract} the attacked cell.

There is a special fire patrol which has its headquarters in the central security post, with which 1,075 automatic devices are connected to give the alarm. If it happens to be a cabin, a red alarm light appears in the corridor. No bell system is installed in order to avoid the risk of a false alarm among the passengers should a bell ring accidentally. In the engine rooms, an outbreak is safeguarded against by means of a hose supplied with carbonic acid foam. In the lower parts of the ship, a plentiful introduction of carbonic gas can be arranged and in the upper parts there are numbers of fire extinguishers. Flying scaffolds are provided so that it is possible to introduce a hose, fed from an upper deck through a porthole, or shut the porthole should it allow a draught. The officers, staff and men who maintain this safety service are specially recruited for the purpose.

The electric lighting system is of low voltage
(110 volts) and the power and lighting wires are everywhere kept separate. It is possible to cut off the electric supply from the single zone where a fire might originate. The fight against the outbreak and the normal life on board are thus not interfered with. In the main public rooms, marbles, onyx, plaster of Paris and glass (moulded or worked) have been used as much as possible. Furniture is either of metal or of a fire-resisting wood. Safety paints and varnishes are employed; all of them were tested to see that their burning point was not less than $400^{\circ} \mathrm{C}$., and that their liability to spread fire was less than a certain fixed standard.

As the length of the Normandie is $1,029 \mathrm{ft}$. and the breadth at the overhang of the promenade deck is $120 \mathrm{ft}$., it is out of the question to use oil engines on account of the power that has to be developed, the weight and size of the engines and the risk of vibration resulting from the use of reciprocating moving parts. Water tube boilers and steam turbines were therefore chosen. Electrical transmission of the power generated to the propellers was chosen because of the absence of noise. It has, however, the disadvantage that it cannot be reversed, and so separate machinery has to be used for going astern. A double hull protects the two rooms where all the machinery is located.

The main power station has four 33,400 kilowatt turbo-alternators which run at 2,430 r.p.m., which is ten times faster than the propeller motors. On its first trip, the Normandie captured the coveted 'blue riband' of the Atlantic, going westward at an average speed of 29.98 knots and returning at $30 \cdot 31$ knots.

In all fast ships, vibration appears and is troublesome at definite speeds, and the Normandie is no exception. Alterations are being carried out during this winter to remedy this inconvenience, and the Compagnie Générale Transatlantique believes that they will be successful. 